(RESEARCH ARTICLE)

\title{
Evaluation of the oxytocic and haematogical effects of leaves of Carica papaya Linn (Caricaceae)
}

\author{
Odoh Uchenna Estella $1{ }^{*}$, Osadebe Patience Ogoamaka ${ }^{2}$ and Etienne Felix Emmanuel 1 \\ ${ }^{1}$ Department of Pharmacognosy and Environmental Medicines, Faculty of Pharmaceutical Sciences, University of Nigeria, \\ Nsukka. \\ ${ }^{2}$ Department of Pharmaceutical and Medicinal Chemistry, Faculty of Pharmaceutical Sciences, University of Nigeria, \\ Nsukka.
}

Publication history: Received on 20 May 2020; revised on 26 May 2020; accepted on 27 May 2020

Article DOI: https://doi.org/10.30574/wjarr.2020.6.2.0164

\begin{abstract}
The aim of this study is to investigate the oxytocic activity of the methanol leaf extract of Carica papaya Linn (Caricaceae) and its effect on haematological parameters. Phytochemical analysis and acute toxicity also studied using standard methods. The Carica papaya leaves were extracted with 10 liters of methanol. The Carica papaya methanol leaf extract (CPMLE) was given at dose of 100, 200 and $400 \mathrm{mg} / \mathrm{kg}$ once daily. The oxytocic effect was done using in-vitro method of isolated rat uterus tissue. Oxytocin and acetylcholine used as standard drugs. The weight and blood samples were taken from animals every seven days for twenty- one days while being fed. Haematological study was done using invivo method on pregnant and non-pregnant Swiss albino rat. The studied doses of CPMLE cumulatively applied to the bath-fluid caused dose related, significant increase in baseline tone and induced spontaneous, rhythmic, myogenic contractions of the uterine muscle strips taken from stilbesterol-pretreated, non-pregnant female and pregnant rats. There was significant $(\mathrm{p}<0.05)$ increase in mean haemoglobin concentration, red blood cell count and packed cell volume as compared to control receiving distilled water. There was a significant $(\mathrm{p}<0.05)$ decrease in the white blood cell count in the test groups relative to that observed in the control group. The preliminary phytochemical analysis showed that CPMLE contained saponins, carbohydrates, alkaloids, glycosides etc. The extract caused no deaths up to $5000 \mathrm{mg} / \mathrm{kg}$ showing the extract is relatively safe. In conclusion, the results show that CPMLE do possess oxytocic and hematological effect.
\end{abstract}

Keywords: Carica papaya; Haematological Analysis; Phytochemical Studies; Oxytocic; Acute Toxicity Studies.

\section{Introduction}

Numerous herbs have been reportedly used historically by women to aid child delivery, stimulate menstrual flow or reduce fertility [1]. Oxytocics can be defined as "any drug that stimulates the smooth muscles of the uterus to contract. The administration of an oxytocic can initiate and enhance rhythmic uterine contraction at any time, but relatively high doses are required for such responses in early pregnancy. Oxytocic agents commonly used include oxytocin, certain prostaglandins, and the ergot alkaloids. These drugs are used to induce or augment labor at term, control postpartum hemorrhage, correct postpartum uterine atony, produce uterine contractions after cesarean section or other uterine surgery, and induce therapeutic abortion.

Oxytocin is normally produced in the hypothalamus and stored in the posterior pituitary gland. It plays a role in intimacy, sexual reproduction of both sexes, and during and after childbirth as well as social bonding. It is released in large amounts after distension of the cervix and uterus during labor and with stimulation of the nipples following childbirth. This helps with birth, maternal bonding, and lactation. Studies have looked at oxytocin's role in various behaviors, including orgasm, social recognition, pair bonding, anxiety, and maternal behaviors. As a medication, it is

\footnotetext{
* Corresponding author: Odoh Uchenna Estella
} 
used to cause contraction of the uterus, which is used to start labour, increase the speed of labor, and to stop bleeding following delivery [2].

Oxytocin is a nonapeptide hormone best known for its role in lactation and parturition. Oxytocin also plays an important physiological role in milk ejection. Stimulation of breasts through suckling and mechanical manipulation induces Oxytocin secretion, causing contraction of the myoepithelium that surrounds areolar channels in the mammary gland. The action forces milk from the alveolar channels into large collecting sinuses where it is available for the suckling infant [3].

The use of herbal medicine to alleviate problems associated with gynaecological conditions of menstruation and menopause, to support health during pregnancy and to facilitate childbirth is common amongst many traditional cultures. Many plants are known to possess oxytocic activity;

Aspilia mossambicensis [4], Byrsocarpus coccineus [5], Citrus hystrix [6], Erythroxylum coca [7], Monechma ciliatum [8], Solanum americanum [9], Spondias mombin [10], Piper guineense [11], Prorocentrum lima [12], Montanoa tomentosa [13].

Carica papaya Linn (Caricaceae) sometimes called pawpaw, is a giant herbaceous plant resembling a tree but not woody. Though the exact area of origin is unknown, the papaya is believed native to Tropical America, perhaps in Southern Mexico and neighbouring Central America. Successful commercial production today is primarily in Hawaii, Tropical Africa, The Philippines, India, Ceylon, Malaysia and Australia, apart from the widespread but smaller scale production in South Africa, and Latin America. In India, papaya is cultivated in Maharashtra, Bengal, Bihar, Haryana, Punjab, Delhi, Andhra Pradesh and Uttar Pradesh [14]. The flesh of the fruit varies from yellow to orange to red, and is thick and juicy, with a central cavity filled with many small black seeds [14].

Carica papaya Linn is one of the valuable plant used for various purposes in medicinal field. Leaves, fruit and seeds of are used as ethno medicine. Applying the lotion of the leaves stops bleeding and shrinks the haemorrhoids [15]. The tender leaves are used as spinach. Leaves are smoked and inhaled in place of tobacco for the relief in asthma. These are believed to be cardiotonic and also promote sweating hence used in fever also. A fine paste of young leaves (5 - $6 \mathrm{~g}$ ) is taken internally in severe cases of jaundice. The infusion of tender leaves is used for various urinary complaints and gonorrhoea [16]. Previous scientific investigations have shown that it has lots of activities. It normalizes the pulse rate in fever and acts as diuretic when administered as decoction [17]. It is attributed to exterminate cough and respiratory, liver and spleen related diseases as well as useful in loss of appetite and oedema [18]. Leaves of Carica papaya L. are used in severe jaundice [19] to expel guinea worm [20], as a poultice [21]; in fracture healing [22], constipation and indigestion [23]. It has been used to treat oral candidosis, malaria, dengue, yellow fever [24] and as a diuretic in dengue related anaemic $[25 ; 26 ; 27 ; 28]$ etc. The seed extract shows hypoglycemic and hypolipidemic activity as well as antifungal and antibacterial activity. The aqueous seed extract has antihelminthic activity. The unripe seed is nephroprotective. The latex shows uterotonic activity [29].

The aim of this study is to investigate the oxytocic activity of the methanol leaf extract of Carica papaya and also observe its effect on the haematological parameters.

\section{Material and methods}

\subsection{Collection and preparation of plant material}

The fresh leaves of Carica papaya were collected from Hilltop village, Nsukka, Enugu state, Nigeria and identified by Mr. Ozioko,a taxonomist with International Centre for Ethnomedicine and Drug Development (InterCEDD) Nsukka. The leaves were carefully separated, dried and grounded using Lab mill, serial no 4745, Christy and Norris Ltd, England. The ground leaf was weighed and stored in an air tight container till needed.

\subsection{Animal}

Adult swiss rats (110-150 g) and mice (13-25 g) of both sexes were obtained from the animal facility of the department of Pharmacology and Toxicology, University of Nigeria, Nsukka. They were housed in metal cages within the facility and allowed free access to standard livestock feed and water ad libitum. Approval for the use of animal subjects was secured from the Animal Research Ethics Committee, University of Nigeria, Nsukka.The animals were handled according to International protocol for handling laboratory animals as documented in the European Community guideline, revised Council Directive, 2010/63/EU. 


\subsection{Extraction}

The powdered material was extracted using the process of cold maceration. About $1200 \mathrm{~g}$ of the ground leaves were weighed and soaked with 10 liters of 95\% methanol in an air tight flask. The mixture was allowed to stand for 3 days with intermittent agitation to facilitate extraction. At the end of the third day, the sample was filtered using Whatman no.4 filter paper and the extracted material was evaporated using a rotary evaporator. After this procedure, an oily and gummy extract was obtained.

\subsection{Phytochemical analysis}

The preliminary phytochemical analysi wer carried ourt todetect the presence of the active constituents present in the plant such as alkaloids, flavonoids, saponins, tannins, glycosides etc and was carried out based on procedure by Trease and Evans [30].

\subsection{Acute toxicity studies (LD50)}

The acute toxicity and lethality (LD50) of the Carica papaya methanol leaf extract (CPMLE) in mice ( $n=12$ ) was estimated using the method described by Lorke [31]. The study was carried out in two stages. In stage one, 9 mice were placed in three groups $(\mathrm{n}=3)$ and treated with oral administration of 10,100 and $1000 \mathrm{mg} / \mathrm{kg}$ of CPMLE (suspended in $3 \%$ tween 80) respectively and was observed for 24 hours. The number of dead animals and the death pattern in the first stage determines the doses used in the second stage (Lorke, 1983).

In stage two, a different batch of mice ( $\mathrm{n}=1$ per group) received 1600, 2900 and $5000 \mathrm{mg} / \mathrm{kg}$ of CPMLE respectively and were observed for 24 hours for deaths and the number of deaths were recorded [31].

\subsection{Oxytocic studies}

The experiment was based on the method of Akah et al., [32] using a pregnant and a non-pregnant Swiss albino rat. The non-pregnant Swiss albino rat was injected with Stilbesterol $(0.1 \mathrm{mg} / \mathrm{kg})$ intramuscularly 24 hours before the experiment. Both rats were killed. The two uterine horns of the animals were cleaned free from fatty and connective tissues and trimmed. Tubular segments of approximately equal length $(2-3 \mathrm{~cm})$ were removed from the uterine horns by cutting of both ends and then transferred to a petri dish containing Tyrode solution. The tissue gotten from the pregnant rat was threaded at the top and the bottom; the bottom thread was attached to the tissue- holder, while the thread is attached to the recording device.

The preparation was subjected to a resting tension of $1.0 \mathrm{~g}$ and allowed to equilibrate for $30-45$ minutes before it was challenged with CPMLE Graded doses of acetylcholine and oxytocin was administered; 2, 4 and 8 ug for acetylcholine; 1, 2, 4 and 8 ug for oxytocin, to establish their effect. Subsequently, Doses of CPMLE were added to the bath fluid sequentially, and washed out 3-4 times after the maximum responses of the tissues were attained. Distilled water (i.e. the vehicle) in which CPMLE was dissolved was used as control fluid for MLE. Concentrations of bath applied CPMLE were repeated where appropriate and/or regular intervals of 3-20 minutes after the last washing. The CPMLE induced responses of the uterine muscle preparations were recorded isometrically by means of the force-displacement transducer. This similar procedure was repeated for the pregnant rat.

\subsection{Evaluation of haematological parameters}

The determination of the blood sample collection, differential leucocyte count, packed cell volume, haemoglobin concentration, red blood cell count, and white blood cell count was done according to Odoh et al., [33]. Blood collection was through the optical plexus of the rats using a heparinized (plain) haematocrit capillary. The blood sample was placed in an EDTA bottle for storage and collection for experiment.

\subsubsection{Differential leucocyte count}

A thick blood film was made on a grease free microscope slide and was allowed to dry. The dry blood film was stained with Leishman stain and was washed off after ten minutes and was allowed to air-dry. The prepared slide was viewed in the microscope, while the neutrophils and the lymphocytes were counted and their percentage composition calculated.

\subsubsection{Packed cell volume (PCV)}

Haematocrit capillary tube was filled with blood by placing one of the open ends of the tube in the blood bottle and tilting it at an angle about 30o. One end of the filled capillary tube was sealed with a plastercine and the tube centrifuged 
for 20 minutes at $300 \mathrm{rpm}$ in a haematocrit centrifuge. A haematocrit reader was used to read off the length of the packed cell in percentage

\subsubsection{Haemoglobin $(\mathrm{Hb})$ concentration}

Sahli haemoglobinometre was used for the determination of haemoglobin concentration. Up to the ten (10) mark of the Sahli tube was $0.1 \mathrm{~N} \mathrm{Hcl}$ placed. With the Sahli blood pipette, $20 \mu \mathrm{l}$ of blood was placed into the Sahli tube and was sucked up and down. The mixture was allowed to stand for 5 minutes for the formation of acid haematin. The dark mixture formed was diluted gradually with distilled water till the colour when compared with that in the haemoglobinometre is slightly darker than the standard. The dilution continued till the colour turns exactly and slightly paler than the standard. The volumes of the noted colour change were taken and the average of the of the slightly darker and paler were compared and was ensure that the variation is not more than \pm 5 for the average value to be adopted. The average value was applied in the formula below:

$\mathrm{X}(\mathrm{Y}) / 100$ where $\mathrm{X}$ is the $14 \mathrm{~g} \mathrm{Hb}$ in $100 \mathrm{ml}$ of blood, $\mathrm{Y}$ is the average value of dilutions.

\subsubsection{Red blood cell (RBC) count}

The following equipment were used for the experiment; the microscope, haemocytometre (counting chamber), red cell pipette, ringer solution and cover slip. Using the dilution pipette with RED mixer from haemocytometer kit, blood was drawn up to the 0.5 mark. Continuing to hold the pipette as horizontal as possible, Ringer's solution diluent was drawn up to the 101 mark (Dilution of 1 to 200). The tip of the pipette was sealed with the finger and shaken well to mix.

Half of the content of the pipette was emptied into a waste container and a small amount of the diluted blood was placed into one chamber of the haemacytometer to just fill the chamber of the haemacytometer. The preparation was allowed to sit for a minute (for cells to settle). The center of the grid was focused with $100 \mathrm{x}$ objective and was counted with $400 \mathrm{x}$ objective. The count of each five fields (each with 16 smallest squares) with a clicker (fields: top right and left, bottom right and left, center) was noted. Include in the count all cells touching left and bottom sides, ignore cells touching top and right sides. The RBCs per $\mathrm{cm} 3$ was calculated by adding the cells in the 5 groups and multiplying by 10,000 (i.e., add four zeros).

\subsubsection{Total white blood cell (WBC) count}

Same as in RBC except that the diluting fluid is $1.5 \%$ acetic acid tinted with methyl violet. The pipette is similar but with different graduation. Unlike the RBC, the leukocytes cells in the entire 9 big grid was counted and applied in the formula (n x 200/9).

\subsection{Statistical analysis}

Data obtained were analysed using one-way ANOVA using graph pad prism 5.04. Results were presented as mean \pm SEM. Differences between means of treated and control groups were accepted significant at $\mathrm{p}<0.05$, Dunnett's post-hoc LSD test [34].

\section{Results}

\subsection{Percentage yield of the extract}

The extraction process yielded 33\% of Carica papaya methanol leaf extract (CPMLE).

\subsection{Phytochemical Constituents of Extract}

The phytochemical analysis showed that CPMLE tested positive to saponins, carbohydrate, alkaloids, glycosides, proteins, terpenoids, tannins, resins, oils and steroids. The results were shown in Table 1. 
Table 1 Phytochemical analysis of Carica papaya leaf extract

\begin{tabular}{lc}
\hline Constituents & Relative abundance \\
\hline Alkaloids & + \\
Carbohydrate & + \\
Flavonoids & - \\
Glycosides & + \\
Oils & + \\
Proteins & + \\
Reducing sugar & - \\
Resins & + \\
Saponins & + \\
Steroids & + \\
Terpenoids & + \\
Tannins & + \\
\hline
\end{tabular}

\subsection{Acute toxicity}

The extract caused no deaths in the first 24 hours among the three groups of mice that received 10, 100, 1000 mg/kg. Also no deaths occurred at the end of the next 24 hours with the second set of three groups that received 1600, 2900, $5000 \mathrm{mg} / \mathrm{kg}$. This shows that the extract is relatively safe and has a wide range of $E D_{50}$. The results were shown in Table 6.

Table 2 Acute toxicity of Carica papaya leaf extract

\begin{tabular}{llll}
\hline Stage of test & Extract & Dose $(\mathrm{mg} / \mathrm{kg})$ & Mortality \\
\hline 1 & MLE & 10 & $0 / 3$ \\
& & 100 & $0 / 3$ \\
& & 1000 & $0 / 3$ \\
2 & MLE & 1600 & $0 / 1$ \\
& & 2900 & $0 / 1$ \\
& 5000 & $0 / 1$ \\
Control & & $0 / 1$ \\
\hline
\end{tabular}

\subsection{Oxytocic studies}

\subsubsection{Pregnamt models}

In the pregnant model, after the viability test, $1,2,4,8,16$ and $32 \mu \mathrm{g}$ of Oxytocin (an exogenous uterine stimulant) on the pregnant rat uterus tissue gave several dose-related contractions on the kymograph. 1, 2, 4, 8, 16, 32, 64 $\mu \mathrm{g}$ of acetylcholine (a known oxytocic agent) also showed contractions on the kymograph. A 20, 40, 80, 160 and 320 mg of CPMLE showed a spontaneous rhythmic contraction almost immediately as compared with the oxytocic effect of Acetylcholine and Oxytocin. Figures 1-5 illustrates a typical trace obtained. 


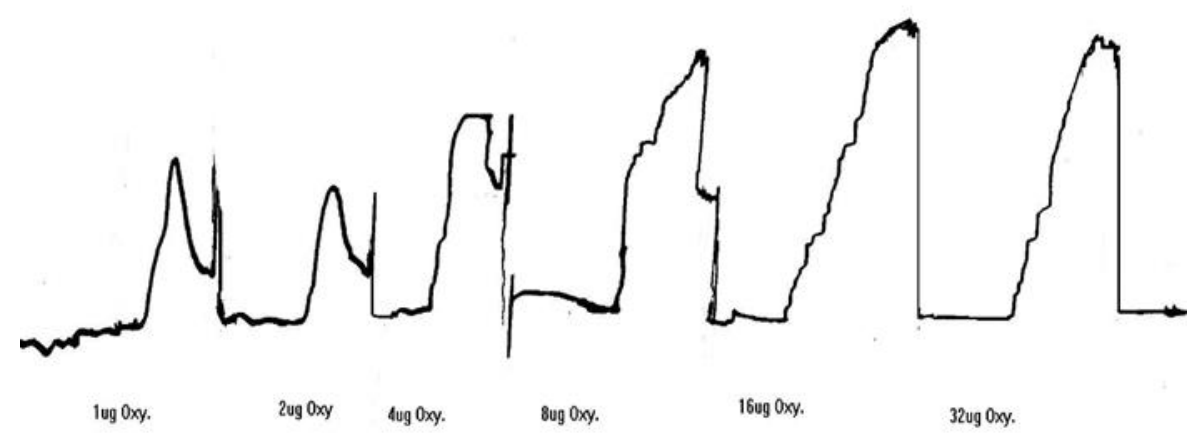

Figure 1 Effect of Oxytocin on rat uterus (pregnant model)

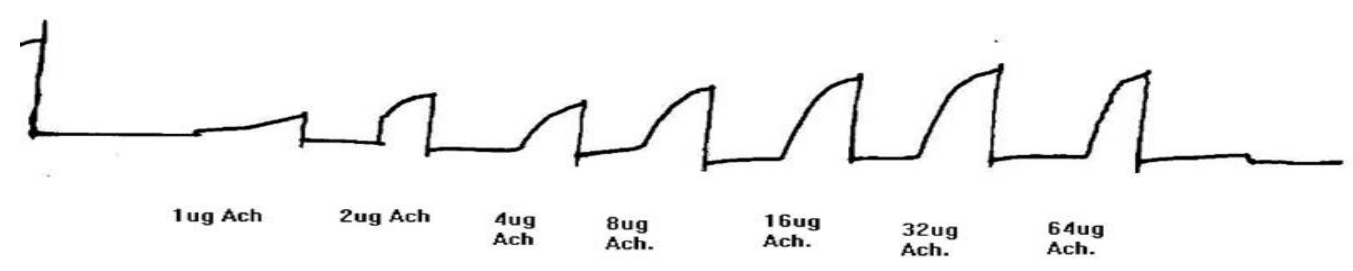

Figure 2 Effect of acetylcholine on rat uterus (pregnant model)

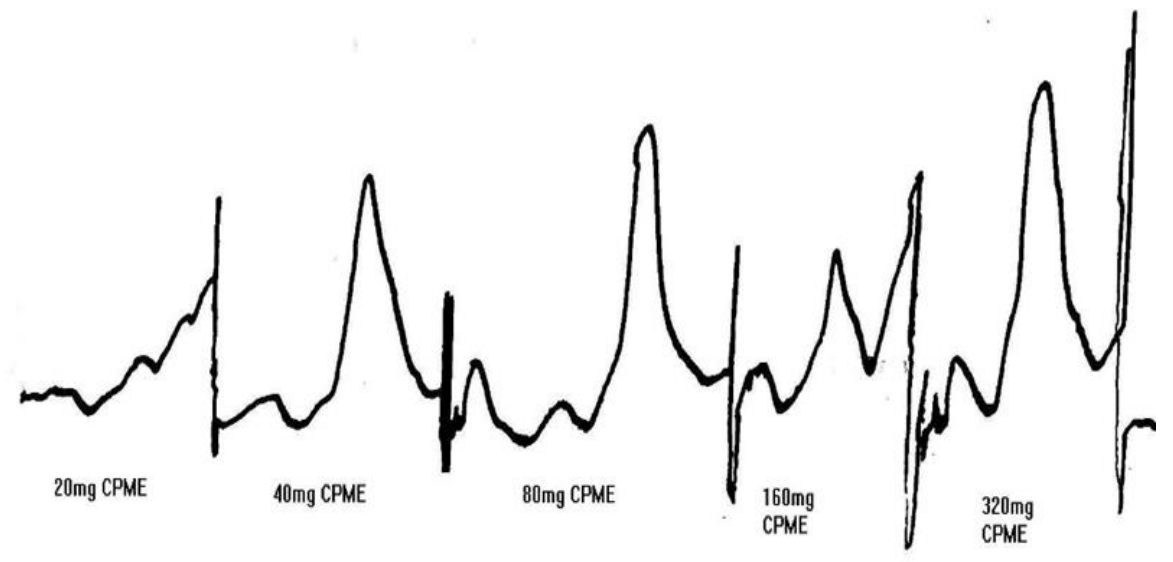

Figure 3 Effect of CPMLE on rat uterus (pregnant model) 


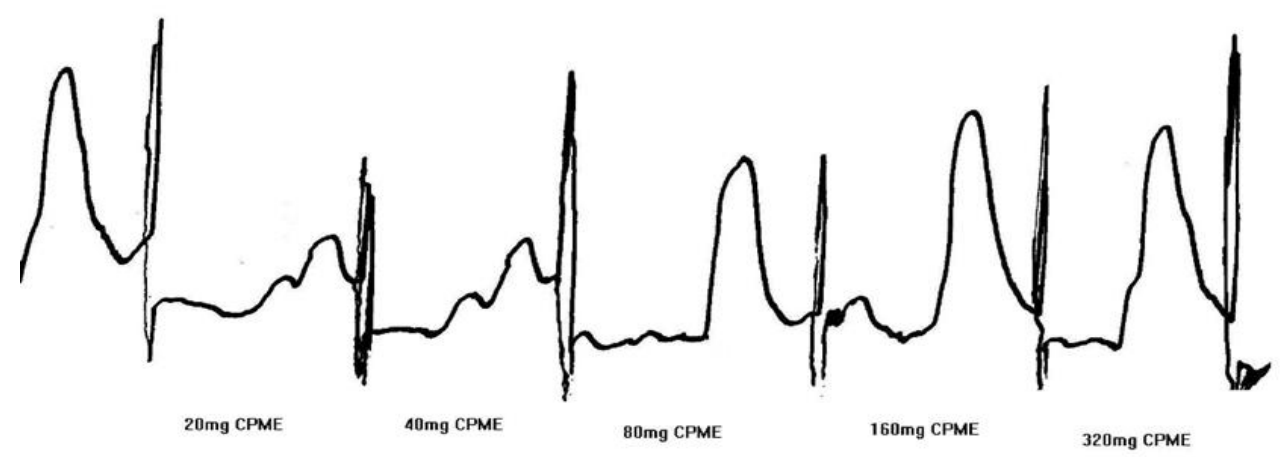

Figure 4 Effect of CPMLE on rat uterus (pregnant model)

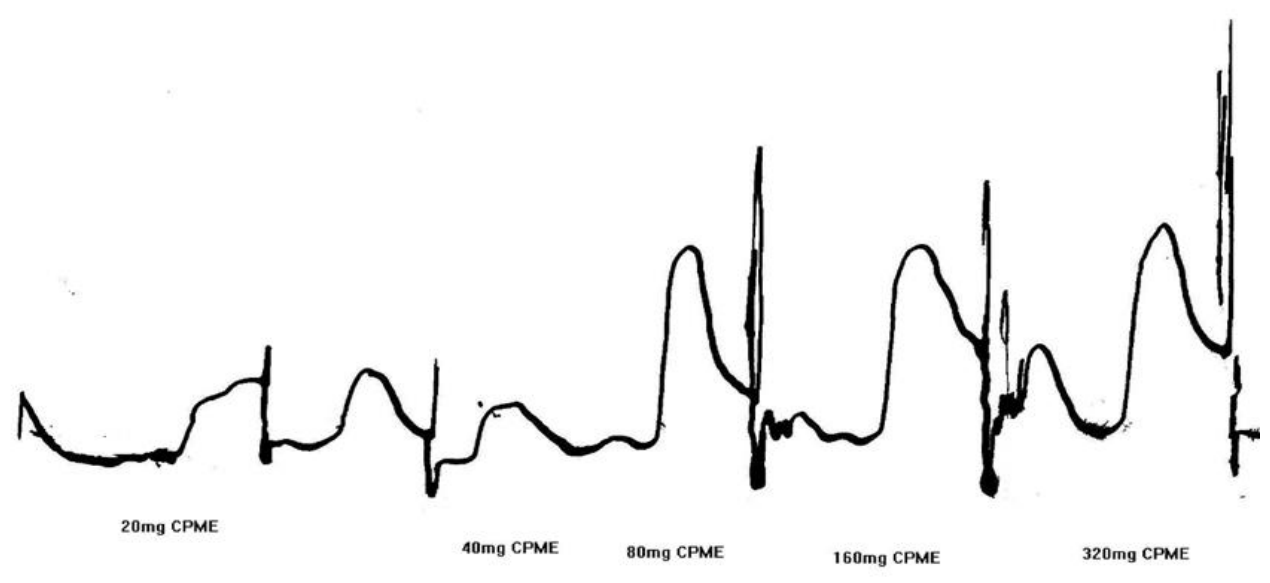

Figure 5 Effect of CPMLE on rat uterus (pregnant model)

\subsubsection{Non-pregnant model}

After the viability test, 1, 2, 4 and $8 \mu \mathrm{g}$ of Oxytocin and 1, 2, 4 and $8 \mu$ g Acetylcholine gave contractions respectively when applied on the non-pregnant rat uterus tissue. A 20,40, 80, $160 \mathrm{mg}$ of CPME contracted the uterus tissue. Then a coadministration of $20 \mathrm{mg}$ of CPMLE and $8 \mu \mathrm{g}$ of oxytocin as well as a $20 \mathrm{mg}$ of CPMLE and $4 \mu \mathrm{g}$ of acetylcholine gave a dose-related increase in the basal tone of uterine contractions signifying potentiation. Figures 6-11 illustrates a typical trace obtained.

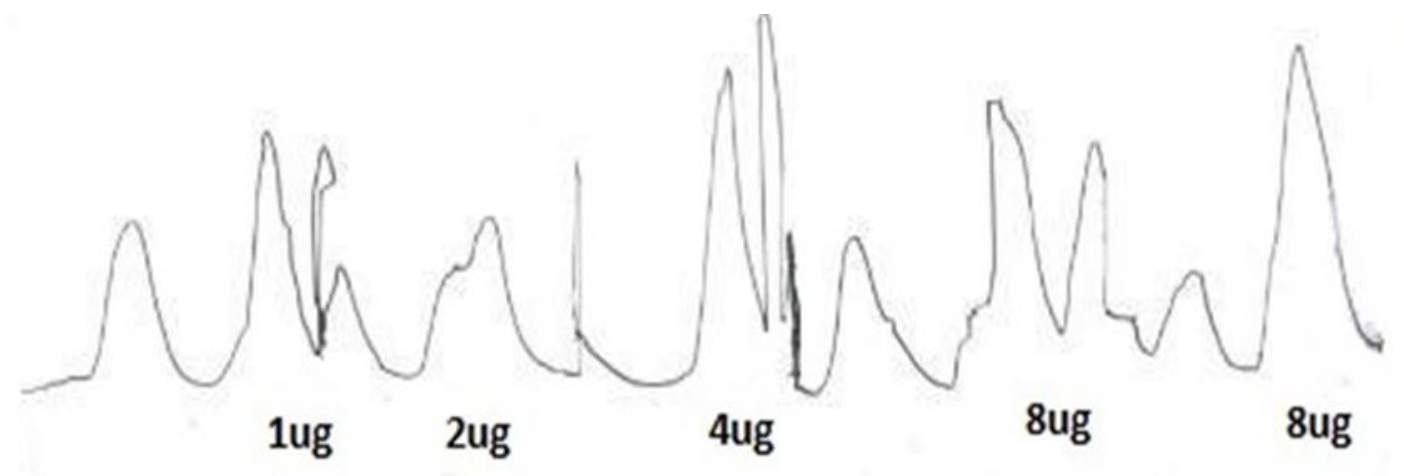

Figure 6 Effect of Oxytocin on rat uterus (non-pregnant model) 


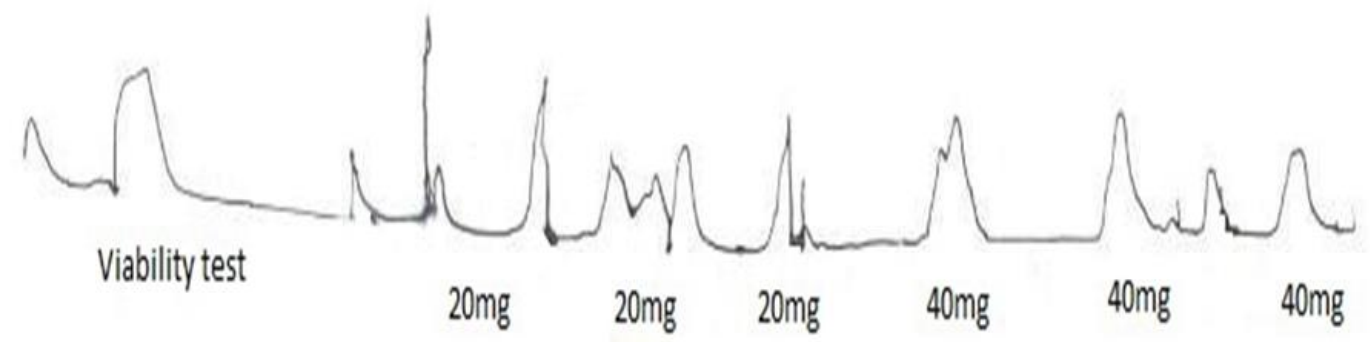

Figure 7 Effect of CPMLE on rat uterus (non-pregnant model)

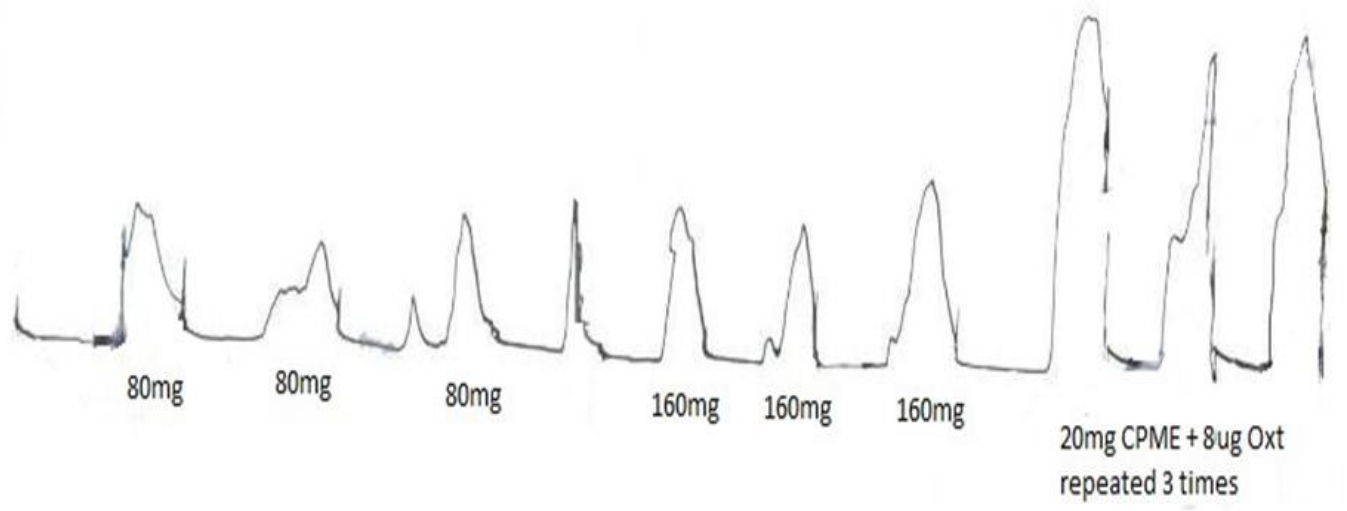

Figure 8 Effect of CPMLE on rat uterus showing potentiation with oxytocin (non-pregnant model)

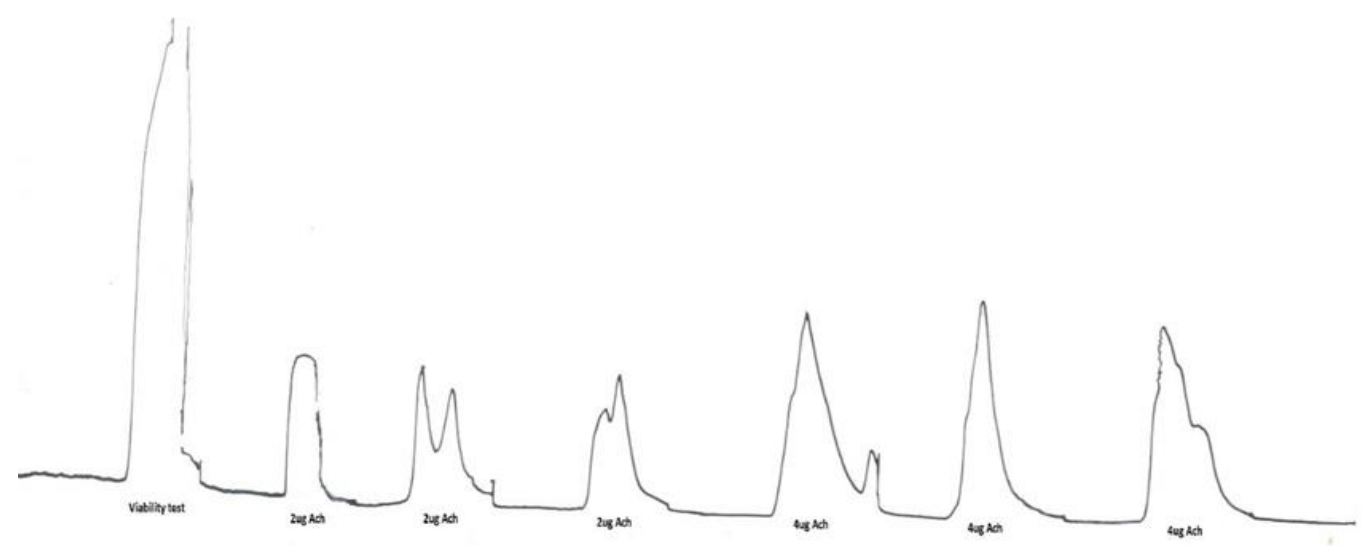

Figure 9 Effect of acetylcholine on rat uterus (Non-pregnant model) 


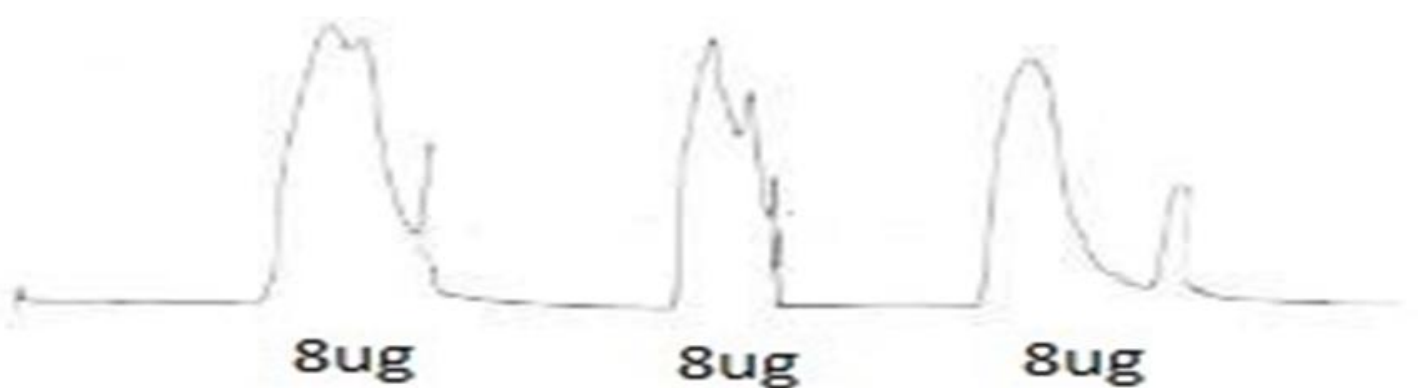

Figure 10 Effect of acetylcholine on rat uterus (Non-pregnant model)

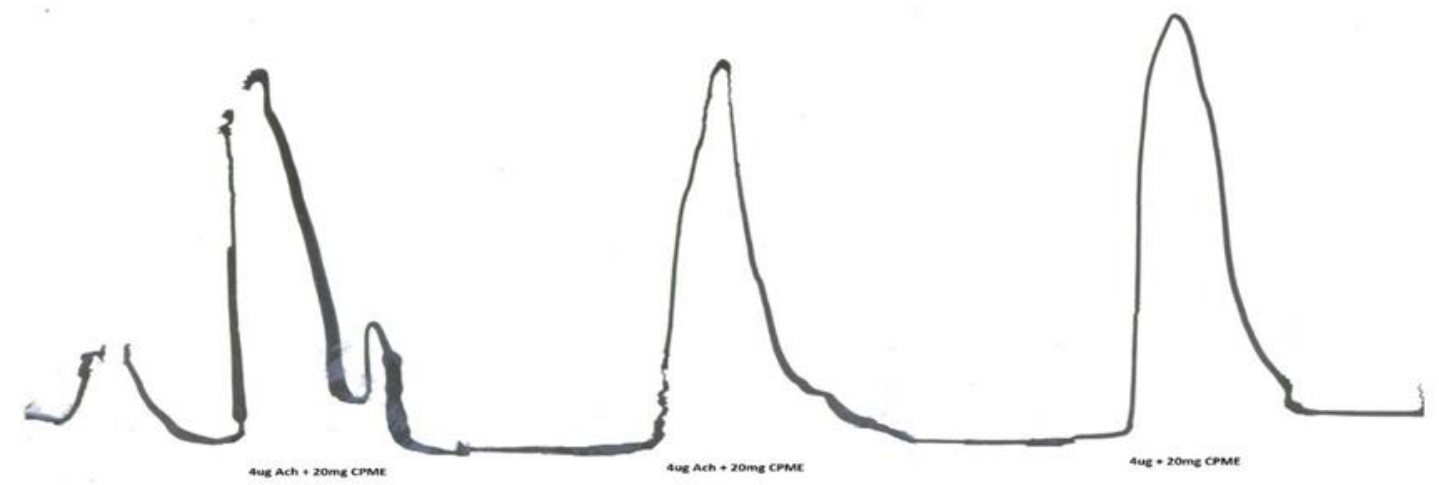

Figure 11 Effect of acetylcholine and CPMLE on rat rterus showing potentiation

\subsection{Haematological Analysis}

\subsubsection{The effect of CPMLE on Haemoglobin Concentration}

The results showed that $400 \mathrm{mg} / \mathrm{kg}$ of CPMLE increased the haemoglobin concentration significantly on day 7. The dose of 100 and $200 \mathrm{mg} / \mathrm{kg}$ maintained a steady increase on day 14; 200 and $400 \mathrm{mg} / \mathrm{kg}$ increased the haemoglobin concentration on day 21 (Table 3).

Table 3 Result of the effect of CPMLE on haemoglobin (Hb) concentration (g/dl)

\begin{tabular}{|c|c|c|c|c|c|c|}
\hline Treatment & & Dose (mg/kg) & Day 0 & Day 7 & Day 14 & Day 21 \\
\hline CPMLE & & 100 & $10.67 \pm 0.37$ & $11.00 \pm 0.25$ & $15.00 \pm 0.20$ & $14.50 \pm 0.41$ \\
\hline CPMLE & & 200 & $10.98 \pm 0.49$ & $11.54 \pm 0.35$ & $16.52 \pm 0.32 *$ & $16.02 \pm 0.40^{*}$ \\
\hline CPMLE & & 400 & $10.86 \pm 0.51$ & $12.98 \pm 0.61^{*}$ & $15.76 \pm 0.35^{*}$ & $15.84 \pm 0.33^{*}$ \\
\hline $\begin{array}{l}\text { Distilled water } \\
\mathrm{ml} / \mathrm{kg} \text { ) }\end{array}$ & $(5$ & - & $10.74 \pm 0.47$ & $10.50 \pm 0.45$ & $14.58 \pm 0.27$ & $13.96 \pm 0.20$ \\
\hline
\end{tabular}

Values represented as Mean \pm SEM of the results from triplicate analysis, ${ }^{*} \mathrm{p}<0.05$ significant. Comparison with control group; CPMLE $=$ Carica papaya Methanol leaf extract

\subsubsection{The effect of CPMLE on PCV}

CPMLE at a dose of $400 \mathrm{mg} / \mathrm{kg}$ increased the PCV was increased on day 7 while 200 and $400 \mathrm{mg} / \mathrm{kg}$ also increased PCV on days 14 and 21 with respect to the negative control (Table 4). 
Table 4 Result of the effect of CPMLE on PCV (\%)

\begin{tabular}{llllll}
\hline Treatment & Dose $(\mathbf{m g} / \mathbf{k g})$ & Day 0 & Day 7 & Day 14 & Day 21 \\
\hline CPMLE & 100 & $31.00 \pm 1.00$ & $32.20 \pm 0.73$ & $50.75 \pm 2.81$ & $42.50 \pm 1.26$ \\
CPMLE & 200 & $32.20 \pm 1.16$ & $33.80 \pm 1.02$ & $67.20 \pm 3.47^{*}$ & $48.60 \pm 1.47^{*}$ \\
CPMLE & 400 & $32.00 \pm 1.38$ & $38.80 \pm 2.44^{*}$ & $59.20 \pm 3.68^{*}$ & $48.40 \pm 1.29^{*}$ \\
$\begin{array}{l}\text { Distilled water } \\
\text { (5 ml/kg) }\end{array}$ & & $31.60 \pm 1.29$ & $31.50 \pm 0.87$ & $47.75 \pm 1.03$ & $41.20 \pm 0.97$ \\
\hline
\end{tabular}

Values represented as Mean \pm SEM of the results from triplicate analysis, ${ }^{*} \mathrm{p}<0.05$ significant. Comparison with control group; CPMLE $=$ Carica papaya Methanol leaf extract

\subsubsection{The effect of CPMLE on $R B C$}

CPMLE at a dose of $400 \mathrm{mg} / \mathrm{kg}$ increased the RBC count significantly on day 7 while 200 and $400 \mathrm{mg} / \mathrm{kg}$ also caused an increase on days 14 and 21 (Table 5).

Table 5 Result of the effect of CPMLE on RBC $(* 106$ cells $/ \mathrm{mm} 3)$

\begin{tabular}{|c|c|c|c|c|c|}
\hline Treatment & Dose (mg/kg) & Day 0 & Day 7 & Day 14 & Day 21 \\
\hline CPMLE & 100 & $3.00 \pm 0.34$ & $3.36 \pm 0.09$ & $4.58 \pm 0.19$ & $4.61 \pm 0.24$ \\
\hline CPMLE & 200 & $3.21 \pm 0.15$ & $3.44 \pm 0.17$ & $5.58 \pm 0.34^{*}$ & $5.00 \pm 0.18^{*}$ \\
\hline CPMLE & 400 & $3.16 \pm 0.13$ & $3.98 \pm 0.27^{*}$ & $5.30 \pm 0.20^{*}$ & $5.01 \pm 0.15^{*}$ \\
\hline $\begin{array}{l}\text { Distilled water (5 } \\
\mathrm{ml} / \mathrm{kg})\end{array}$ & & $3.10 \pm 0.15$ & $3.10 \pm 0.12$ & $4.39 \pm 0.11$ & $4.13 \pm 0.06$ \\
\hline
\end{tabular}

\subsubsection{The effect of CPMLE on $W B C$}

The results showed that there was an increase in the WBC count with the dose of 400mg/kg of CPMLE on day 7. Also there was a significant reduction in WBC count with the dose of $200 \mathrm{mg} / \mathrm{kg}$ on day 14 before returning to normal on day 21 (Table 6).

Table 6 Result of the effect of CPMLE on WBC (*106 cells/mm3)

\begin{tabular}{|c|c|c|c|c|c|}
\hline Treatment & Dose (mg/kg) & Day 0 & Day 7 & Day 14 & Day 21 \\
\hline CPMLE & 100 & $5878.4 \pm 220.85$ & $6708.0 \pm 177.49$ & $5572.5 \pm 340.69$ & $5745.0 \pm 314.89$ \\
\hline CPMLE & 200 & $6392.0 \pm 424.13$ & $6664.0 \pm 192.91$ & $4810.0 \pm 145.95^{*}$ & $5136.8 \pm 309.68$ \\
\hline CPMLE & 400 & $6444.4 \pm 335.65$ & $5882.0 \pm 158.70 *$ & $4956.0 \pm 378.12$ & $4836.0 \pm 382.02$ \\
\hline $\begin{array}{l}\text { Distilled water (5 } \\
\mathrm{ml} / \mathrm{kg} \text { ) }\end{array}$ & & $6688.4 \pm 198.44$ & $7195.5 \pm 226.69$ & $7308.8 \pm 358.85$ & $5644.0 \pm 322.89$ \\
\hline
\end{tabular}

\subsubsection{The effect of CPMLE on neutrophils}

The results showed an increase in neutrophil count on day 7 with the dose of 100 and $200 \mathrm{mg} / \mathrm{kg}$ of CPMLE. It also showed a decrease with the dose of 200 and $400 \mathrm{mg} / \mathrm{kg}$ on days 14 and 21 (Table 7). 
Table 7 Result of the Effect of CPMLE on neutrophils (\%)

\begin{tabular}{llllll}
\hline Treatment & Dose $(\mathbf{m g} / \mathbf{k g})$ & Day 0 & Day 7 & Day 14 & Day 21 \\
\hline CPMLE & 100 & $72.80 \pm 1.02$ & $72.40 \pm 1.50^{*}$ & $64.25 \pm 1.31$ & $66.50 \pm 1.71$ \\
CPMLE & 200 & $73.40 \pm 0.98$ & $68.60 \pm 1.54^{*}$ & $57.60 \pm 2.73^{*}$ & $58.80 \pm 1.02^{*}$ \\
CPMLE & 400 & $71.80 \pm 1.50$ & $42.60 \pm 7.08$ & $60.80 \pm 1.62^{*}$ & $56.40 \pm 1.03^{*}$ \\
$\begin{array}{l}\text { Distilled water } \\
(5 \mathrm{ml} / \mathrm{kg})\end{array}$ & & $72.00 \pm 1.41$ & $28.25 \pm 1.65$ & $70.00 \pm 2.00$ & $70.00 \pm 0.71$ \\
\hline
\end{tabular}

Values represented as Mean \pm SEM of the results from triplicate analysis, ${ }^{*} \mathrm{p}<0.05$ significant. Comparison with control group; CPMLE $=$ Carica papaya Methanol leaf extract

\subsubsection{Effect of CPMLE on lymphocytes}

The results showed a decrease in lymphocyte count on day 7 with the dose of 100 and $200 \mathrm{mg} / \mathrm{kg}$. It also showed an increase with the dose of 200 and $400 \mathrm{mg} / \mathrm{kg}$ on days 14 and 21 (Table 8).

Table 8 Result of the effect of CPMLE on lymphocytes (\%)

\begin{tabular}{|c|c|c|c|c|c|}
\hline Treatment & Dose (mg/kg) & Day 0 & Day 7 & Day 14 & Day 21 \\
\hline CPMLE & 100 & $27.20 \pm 1.02$ & $27.60 \pm 1.50^{*}$ & $35.75 \pm 1.31$ & $33.50 \pm 1.71$ \\
\hline CPMLE & 200 & $26.60 \pm 0.98$ & $31.40 \pm 1.54^{*}$ & $42.40 \pm 2.73^{*}$ & $41.20 \pm 1.02^{*}$ \\
\hline CPMLE & 400 & $28.20 \pm 1.50$ & $57.40 \pm 7.08$ & $39.20 \pm 1.62^{*}$ & $43.60 \pm 1.03^{*}$ \\
\hline $\begin{array}{l}\text { Distilled water } \\
(5 \mathrm{ml} / \mathrm{kg})\end{array}$ & & $28.00 \pm 1.41$ & $71.75 \pm 1.65$ & $30.00 \pm 2.00$ & $30.00 \pm 0.71$ \\
\hline
\end{tabular}

Values represented as Mean \pm SEM of the results from triplicate analysis, ${ }^{*} \mathrm{p}<0.05$ significant. Comparison with control group; CPMLE $=$ Carica papaya Methanol leaf extract

\subsection{Effect on the body weight}

The body weight of the treatment and control rats were as shown in Table 9. There were gradual increases in body weight of treatment and control rats weekly. The body weight of the treatment rats were significantly different as compared to the control rat. There was a significant increase in body weight with the dose of $100,200 \mathrm{and} 400 \mathrm{mg} / \mathrm{kg}$ of CPMLE on day 14 and 21.

Table 9 Result of the effect of CPMLE on body weight

\begin{tabular}{llllll}
\hline Treatment & Dose $(\mathbf{m g} / \mathbf{k g})$ & Day 0 & Day 7 & Day 14 & Day 21 \\
\hline CPMLE & 100 & $122.58 \pm 4.17$ & $152.43 \pm 3.99$ & $157.99 \pm 10.55^{*}$ & $162.40 \pm 3.86^{*}$ \\
CPMLE & 200 & $127.79 \pm 5.04$ & $153.22 \pm 5.34$ & $153.42 \pm 4.63^{*}$ & $150.82 \pm 6.84^{*}$ \\
CPMLE & 400 & $134.50 \pm 5.21$ & $154.00 \pm 6.30$ & $158.76 \pm 4.95^{*}$ & $161.50 \pm 5.30^{*}$ \\
$\begin{array}{l}\text { Distilled water } \\
\text { ml/kg) }\end{array}$ & - & $134.11 \pm 2.66$ & $147.10 \pm 2.92$ & $133.56 \pm 8.35$ & $141.22 \pm 2.94$ \\
\hline
\end{tabular}

Values represented as Mean \pm SEM of the results from triplicate analysis, ${ }^{*} \mathrm{p}<0.05$ significant. Comparison with control group; CPMLE $=$ Carica papaya Methanol leaf extract

\section{Discussion}

The therapeutic value of medicinal plants lies in the various chemical constituents in it. The bioactivity of plant extracts is attributed to its phytochemical constituents [35]. The phytochemical analysis showed that CPMLE tested positive to saponins, carbohydrates, alkaloids, glycosides, proteins, terpenoids, tannins, resins, oils and steroids. Due to the 
presence of saponins in CPMLE it was found that "Saponins has relationship with sex hormone involved in controlling the onset of labor in women and the subsequent release of milk" [36].. With this fact we can attribute its oxytocic effect to the presence of saponins in the methanol leaf extract.

After the acute toxicity study, the extract caused no deaths in the first 24 hours among the three groups of mice that received 10, 100 and $1000 \mathrm{mg} / \mathrm{kg}$. Also no deaths occurred at the end of the next 24 hours with the second set of three groups that received $1600,2900,5000 \mathrm{mg} / \mathrm{kg}$. This shows that the extract is relatively safe and has a wide range of ED50. This is in line with the findings of Halim et al [37]; who reported no mortalities with the aqueous extract. However, there were behavioral changes such as depression, reduced motor activity and ataxia, this could be due to the presence of cyanogenic glycosides in C. papaya [38; 39]. These glycosides have been known to have deleterious effects on the brain due to cytotoxic hypoxia, leading to various degrees of nervous signs [40]. This may be related to the folkloric use of the plant as a muscle relaxant and sedative [41], which has been validated [42].

There was a gradual increase in body weight of treatment and control rats weekly. The increase in body weight of the treatment rats was not significantly different from the control rat. The food and water consumption of the treatment rats were also not significantly different as compared to the control rats measured throughout the study. The increase in body weight of all groups weekly were considered normal and gradually as observed in rats of similar age group in a published reference [43]. The increases in body weight were in line with the increase in food and water consumed by the rats.

After the viability test, 1, 2, 4, 8, 16 and $32 \mu \mathrm{g}$ of Oxytocin (an exogenous uterine stimulant used as the standard drug) was applied to the pregnant rat uterus tissue which gave several dose-related contractions on the kymograph. A 1, 2, 4, $8,16,32,64 \mu \mathrm{g}$ of acetylcholine (a known oxytocic agent) also showed contractions on the kymograph. A 20, 40, 80, 160 and $320 \mathrm{mg}$ of CPMLE when added showed a spontaneous rhythmic contraction almost immediately as compared with the oxytocic effect of Acetylcholine and Oxytocin.

A 100, 200 and $400 \mathrm{mg} / \mathrm{kg}$ dose of CPMLE cumulatively applied to the bath-fluid caused dose related, significant increase in the baseline tone and induced spontaneous, rhythmic, myogenic contractions of the uterine muscle strips taken from stilbesterol-pretreated, non-pregnant female rats. A 200 and $400 \mathrm{mg} / \mathrm{kg}$ dose of CPMLE when sequentially added to the bath-fluid provoked contractions of the uterine muscle preparations. Sequentially applied acetylcholine $(1,2,4$ and $8 \mu \mathrm{g})$ and oxytocin $(1,2,4$ and $8 \mu \mathrm{g})$ also induced dose-dependent, significant contractions of the uterine muscle preparations taken from the non-pregnant rats. A $200-400 \mathrm{mg} / \mathrm{kg}$ dose of CPMLE potentiated Acetylcholine and Oxytocin-induced contractions of the isolated uterine muscle strips in a dose-dependent manner. These similar findings justified the use of Spondias mombin by traditional birth attendants in labor induction, augmentation, and as postpartum astringent [11].

The observations made during the study of the haematological parameters were quite interesting. There was a significant $(\mathrm{p}<0.05)$ increase in mean haemoglobin concentration, red blood cell count and packed cell volume as compared to control receiving distilled water. There was a significant $(\mathrm{p}<0.05)$ decrease in the white blood cell count recorded for rats in the test groups relative to that observed in the control group. These results are in agreement with previous observations of increase in platelet count after treatment with leaf extract of Carica papaya. Carica papaya leaf extract has been found to accelerate the increase in platelet, haemoglobin, PCV and RBC count and shortened the hospitalization period [44].

\section{Conclusion}

In conclusion, it is clear that the methanol extract of Carica papaya leaves induced spontaneous, rhythmic, myogenic contractions of the uterine muscle strips taken from stilbesterol-pretreated, non-pregnant female rats as well as from pregnant rats. It also significantly increased mean haemoglobin concentration, packed cell volume and red blood cell count as compared to the negative control. There was a significant $(\mathrm{p}<0.05)$ decrease in the WBC recorded for rats in the test groups relative to that observed in the control group without causing any acute/subacute toxicity. Therefore, we suggest that Carica papaya leaf extract can be used as a medicine in labor induction and augmentation. However, this is a preliminary study and more work is needed to isolate and to identify the biologically active ingredients of Carica papaya leaves that are responsible for these effects. 


\section{Compliance with ethical standards}

\section{Acknowledgments}

The authors acknowledged Mr. A. O. Ozioko, a taxonomist with the International Centre for Ethnomedicine and Drug Development (InterCEDD) Nsukka, Nigeria for the identification of the plant material.

\section{Disclosure of conflict of interest}

The authors whose names are listed above certify that they have NO affiliations with or involvement in any organization or entity with any financial interest.

\section{Statement of ethical approval}

Approval for the use of animal subjects was secured from the Animal Research Ethics Committee, University of Nigeria, Nsukka. The animals were handled according to International protocol for handling laboratory animals as documented in the European Community guideline, revised Council Directive, 2010/63/EU.

\section{References}

[1] Bodhankar SL, Garg SK and Mathur VS. (1974).Anti-Fertility Screening of Plants, Part IX; Effect of Five Indigenous Plants on Early Pregnancy in Albino Rats. Indian J. Med. Res, 62(6), 831-837.

[2] Wikipedia. (2015).The free Encyclopedia.

[3] Mugisha MK, Oryem-Origa H and Olwa-Odyek\&Makawiti DW. (2010). Ethno-pharmacological screening of Vernonia amygdalina and Cleome gynandra traditionally used in Childbirth in Western Uganda, 11th NAPRECA Symposium Book of Proceedings, Antananarivo, Madagascar, 110-122.

[4] Page JE, Balza F, Nishida T and Towers GHN. (1992). Biologically-active diterpenes from Aspilia mossambicensis, a Chimpanzee medicinal plant. Phytochemistry, 31, 3437-3439.

[5] Amos S, Binda L, Kunle OF, Wambebe C and Gamaniel K. (2002). Uterotonic Properties of the Ethanol Extract of Brysocarpus coccineus. Pharm Biol, 40, 33-38.

[6] Piyachaturawat P, Glinsukon T and Chanjarunee A. (1985). Antifertility effect of Citrus hystrix DC. J Ethnopharmacol, 13, 105-110.

[7] Monga M, Weisbrodt NW, Andres RL and Sanborn BM. (1993). The Acute Effect of Cocaine Exposure on Pregnant Human Myometrial Contractile Activity. am J Obstet Gynecol, 169, 782-785.

[8] Uguru MO, Ekwenchi MM and Evans F. (1999). Bioassay-directed isolation of oxytocic principles from the methanol extract of Monech maciliatum . Phytother Res, 13, 696-699.

[9] Sanchez LM, Bulnes C, Perez P, Rodriguez A, Noa M, Ginorio C and Gomez BC. (2003). Antibacterial, wound healing and isolated uterus activity of Solanum americanum Miller. Actual Biol (Medellin), 25, 71-78.

[10] Nworu CS, Akah PA, Okoli CO and Okoye TC. (2007). Oxytocic activity of leaf extract of Spondias mombin. Pharm Biol, 45, 366-371.

[11] Udoh FV. (1999). Uterine Muscle Reactivity to Repeated Administration and Phytochemistry of the Leaf and Seed Extracts of Piper guineense. Phytother Res, 13, 55-58.

[12] Arteche E, Strippoli G, Loirand G, Pacaud P, Candenas L, Molto JC, Souto L, Fernandez J, Norte M, Martin JD and Savineau JP. (1997). An analysis of the mechanisms involved in the okadaic acid-induced contraction of the estrogen-primed rat uterus. J Pharmacol., ExpTher, 282, 201-207.

[13] Campos Bedolla P, Campos MG, Valencia Sanchez A, Ponce Monter H, Uribe C, Osuna L and Calderon J. (1997). Effect of kauranes from Montanoa spp on rat uterus. Phytother Res, 11, 11-16.

[14] Milind BI, Nwinuka, NM and Monanu MO. (2009). The Effect of Aqueous Extract of Carica papaya leaves on Liver Enzymes and Blood Cell Counts of Normal Albino Rats. International Journal of Biological and Chemical Sciences, $3(3)$. 
[15] Pullaiah T. (2006). Encyclopaedia of World Medicinal Plants. Regency publication, New Delhi, 1, 446-449.

[16] The wealth of India, raw materials Ca-Ci: CSIR, New Delhi (1992). 3, 290.

[17] Trikamji AY. (2001). Dravyagunavigyanam uttaraardha. Sharma ayurved mandir datiya, 5, 212-213.

[18] Bapalal VG. (2007). Nighantu Adarsh Chaukhambha bharati Academy, Varanasi, Reprint, 1, 613-616.

[19] Reddy RK. (1988). Folk medicines from Chittoor district, Andhra Pradesh, India, used in the treatment of Jaundice. International Journal of Crude Drug Research, 26, 137-140.

[20] Raj KPS and Patel MR. (1978). Some medicinal plants of Cambay and its immediate vicinity and their uses in Indian indigenous system of medicine. Indian drugs, 15, 145-152, 160.

[21] Banerjee AK and Banerjee. (1986). A survey of medicinal plants in Shevaroy hills. J Econ Tax Bot, 8, 271-290.

[22] Pal SC and Srivastava SN. (1976). Preliminary notes on the ethnobotany of Singhbhum District, Bihar. Bull. Bot. Surv. India, 18, 247-250.

[23] Megoneitso and Rao RR. (1983). Ethnobotanical studies in Nagaland, sixty two medicinal plants used by the Angami-a Naga, J. Econ. Taxon. Bot, 4(1), 167-172.

[24] Kisangau DP, Hosea KM, Joseph CC and Lyaruu HV. (2007). In-vitro antimicrobial assay of plants used in traditional medicine in Bukoba Rural district, Tanzania. Afr J Tradit Complement Altern Med, 4, 510-523.

[25] Ghoti H, Fibach E, Dana M, Abu Shaban M and Jeadi H. (2011). Oxidative stress contributes to hemolysis in patients with hereditary spherocytosis and can be ameliorated by fermented papaya preparation. Ann Hematol, 90, 509-513.

[26] Aruoma OI, Hayashi Y, Marotta F, Mantello P and Rachmilewitz E. (2010). Applications and bioefficacy of the functional food supplement fermented papaya preparation. Toxicology, 278, 6-16.

[27] Iweala EE, Uhegbu FO and Ogu GN. (2010). Preliminary in-vitro antisickilng properties of crude juice extracts of Persia Americana, Citrus sinensis, Carica papaya and Ciklavit (R). Afr. J. Tradit. Complement Altern Med, 7, 113117.

[28] Sripanidkulchai B, Wongpanich V, Laupattarakasem P, Suwansaksri J, Jirakulsomchok D. (2001). Diuretic effects of selected Thai indigenous medicinal plants in rats. J Ethnopharmacol, 75, 185-190.

[29] Krishna, Paridhavi M and Patel JA. (2008). "Review on Nutritional, Medicinal and Pharmacological Properties of Papaya (Carica papaya Linn.)" Natural Product Radiance, 7(4), 364-373.

[30] Trease GE and Evans WC. (1996). Textbook of Pharmacognosy. (14 ${ }^{\text {th }}$ Ed.) W.B. Sanders, London, 46-47, 832.

[31] Lorke D. (1983). A New Approach to Practical Acute Toxicity Testing. Arch. Toxicol, 54, 275-287.

[32] Akah PA, Ezike AC, Okoye TC, Nworu CS, Nwabunike SI, Mbaoji NF and Onyeto CA. (2014). Experimental methods in physiology (for Medical and pharmacy Students) Book III, 40-42.

[33] Odoh UE, Onugha VO and Chukwube VO. (2016). Evaluation of antidiabetic effect and hematotological profile of methanol extract of Ceiba pentandra G (Malvaceae) stem bark on alloxan-induced diabetic rats. African Journal of Pharmacy and Pharmacology, 10(28), 584-590.

[34] Woodson RF. (1987). Statistical Methods for the Analysis of Biomedical Data, Wiley Series in Probability and Mathematical Statistics: Wiley Chichester, 315-316.

[35] Farooq T. (2014). Phytochemical and Pharmacological Investigation of Carica papaya leaves Linn. East West University.

[36] Okwu DE and Okwu ME. (2004). Chemical Composition of Spondia mombin plants J. Sustain. Agri. Environ, 6, 140147.

[37] Halim SZ, Abdullah NR, Afzan A, Abdul Rashid BA, Jantan I and Ismail Z. (2011). Study of Acute Toxicity of Carica papaya Leaf Extract in Sprague Dawley Rats. J. Med. Plant Res, 5, 1867-1872.

[38] Bennett RN, Kiddle G and Wallsgrov RM. (1997). Biosynthesis of Benzylglucosinolate, Cyanogenic Glucosides and Phenylpropanoids in Carica Papaya. Phytochem, 45, 59-66.

[39] Ayoola PB and Adeyeye A. (2010). Phytochemical and Nutrient Evaluation of Carica Papaya (Pawpaw) Leaves. IJRRAS, 5(3). 
[40] Braide VB and Anika SM. (2007). Environmental Toxicology. Snaap Press Ltd., USA, 31-34.

[41] Ellingwood F. (1919). The American Materia Medica, Therapeutics and Pharmacognosy. Ellingwoods' Therapeutist, USA.

[42] Gupta A, Wambebe CO and Parsons DL. (1990). Central and Cardiovascular Effects of the Alcoholic Extract of the Leaves of Carica papaya. Pharm. Biol, 28, 257-266.

[43] Taconomic Technical Library for Plants. Carica papaya was originally described and published in Species Plantarum 2:1036. 1753. GRIN (2011). "Carica papaya information from NPGS/GRIN". National Germplasm Resources Laboratory, Beltsville, Maryland: USDA, ARS, National Genetic Resources Program. Retrieved 10 October 2015.

[44] Yunita F, Endang H and Jusuf K. (2012). The Effect of Carica papaya L. Leaves Extract Capsules on Platelets Count and Hematocrit Level in Dengue Fever Patient. Int. J. Med. Arom. Plants, 2(4), 573-578.

\section{How to cite this article}

Odoh UE, Osadebe PO and Etienne FE. (2020). Evaluation of the oxytocic and haematogical effects of leaves of Carica papaya Linn (Caricaceae). World Journal of Advanced Research and Reviews, 6(2), 212-226. 